\title{
Willingness to Communicate in Synchronous and Face-to- Face Conversation Modes: A Case Study
}

\author{
Amin Shahini \\ Department of English Language Teaching, Golestan Scientific and Research Branch, Islamic Azad University, Gorgan, Iran
}

Email address:

shahiniamin@gmail.com

To cite this article:

Amin Shahini. Willingness to Communicate in Synchronous and Face-to-Face Conversation Modes: A Case Study. International Journal of Language and Linguistics. Vol. 3, No. 5, 2015, pp. 292-297. doi: 10.11648/j.ij11.20150305.13

\begin{abstract}
Willingness to communicate (WTC) has recently received increasing attention across disciplines of second language acquisition and communication. Part of this attention has been directed towards contexts where this willingness might fundamentally increase - that is online setting. This paper is a case study of an Iranian university student who has been subject to investigation under two modes of synchronous chat and face to face conversation. These two environments have been investigated for grammatical accuracy in terms of correct use of noun pluralization, modifier-noun order, dropping of preposition, and subject-verb agreement. Results indicated that the learner was more willing to communicate in synchronous chat environment with fewer errors in the above mentioned areas rather than the face to face setting. Some pedagogical implications have also been suggested.
\end{abstract}

Keywords: WTC, Synchronous Chat, Face to Face Conversation

\section{Introduction}

WTC has been defined as the probability of one's engagement in communication when he/she finds an opportunity to do so (McCroskey \& Baer, 1985). Dornyei (2005) also defines WTC as "a composite ID variable that draws together a host of variables that have been well established as inflences on second language acquisition and use" (p. 210). This concept not only has become an important concept in explaining first language (L1) and second language (L2) communication but also with increasing emphasis on authentic communication as an essential part of L2 learning and instruction, it has been proposed as one of the key concepts in L2 learning and instruction (Kang, 2005).

WTC importance has been fed by the role that interaction plays in language development. This role has been emphasized in various perspectives such as linguistic (for example, Long 1985), sociocultural (Vygotsky, 1978), and learners perspectives (Stoller, Hodge, \& Kimbrough, 1995) among others. Language development is facilitated through interaction; therefore, it can be assumed that more interaction leads to more language development and learning (Long ibid). That said, it is reasonable to argue that WTC, which has been found to influence the frequency of communication (Yanguas, 2014; Yashima, Zenuk-Nishide, \& Shimizu, 2004), can contribute to second language acquisition (SLA) and needs to be emphasized in L2 pedagogy.

The concept of WTC was basically developed and supported by two camps. The first camp sees WTC as a static predisposition which is stable in the person and subject to no change. Burgoon (1976), as the founder of this school of thought proposed the concept of unwillingness to communicate and argued this unwillingness can be caused by various psychological traits; attitude towards the target community, age and sex, perceived communicative competence and anxiety are among some of these traits in the literature.

However, the second camp maintained that WTC is changeable under pedagogical interventions (Kang op.cit.) and it is not a fixed trait hence under the influence of the situational settings, therefore, the situational aspect of the WTC needs to be emphasized in L2 pedagogy. The desirability towards the interlocutor, intergroup climate, and group's social status are some of the situational factors among others.

\section{WTC: Synchronous Online Communication}

The use of online technology can increase learners' WTC to a great deal in that learners don't experience the inherent 
tension in the face to face mode of conversation. Freiermuth and Jarrell (2006) in an experimental study concluded that computer-mediated communication (CMC) encouraged groups of language learners to outperform the assigned speaking tasks in comparison with the non-CMC mode groups. The authors attributed the $\mathrm{CMC}$ mode outperformance to the use of the computer rather than other variables. Students were not interrupted or inhibited by the teacher or other peers and could find a chance to freely express themselves without worrying about a plethora of factors that may have intervened with the task.

Use of synchronous online discussion facilitates teaching and enhances learning (Arnold, 2007; Yashima, 2002). Online communications not only help to develop students' language skills, but also spark students' interest and motivation in language learning in general. For instance, Beauvois (1998) found that students enrolled in intermediate French who used an electronic synchronous communication software program (Daedalus Interchange) for class discussion did better on oral exams than those who spent the same amount of time in oral discussion in the classroom.

Literature points to three benefits of CMC. First, CMC provides for more equal participation than face-to- face interaction (Sullivan \& Pratt, 1996). CMC is unique in that it allows shy and less well-motivated learners to interact with others (Kelm, 1992). In terms of modified input and output, learners go through a collaborative process in a social context rather than in isolation. During online collaborative interactions, learners have the opportunity to have all the information handy on the computer screen so that they can copy useful vocabulary, expressions, and linguistic aspects from each other.

Secondly, CMC lends learners enough time to process input, and monitor and edit output through a self- paced learning environment. The learner reads, processes and gives feedback at his or her own pace (Kelm, 1992). Simultaneously, the learner pays attention to certain aspects of discourse on the screen (Warschauer, 1997). The learner reconsiders and revises the content semantically and syntactically to make the interaction more meaningful and comprehensible. In other words, learners' awareness of the language structures that they and their peers use to compose messages will significantly rise. Subsequently, this may encourage them to self-correct lead them to attend to feedback or attempt self-correction frequently. Learners benefit from the focus on form in attempting to overcome incorrect target language features; this internal monitor supports language acquisition.

Finally, CMC increases language production and complexity. As Swain argued, producing output pushes the learner to use the target language which is essential for SLA. The reduction of teacher talk in CMC is in favor of learner language production. Learners receive two or three more turns to use the target language (Freiermuth \& Jarrell, 2006) than they would in the traditional classroom setting (face-toface oral communication). Learner-learner online interaction, therefore, should result in greater language production than that achieved in teacher-learner interaction.

Research into synchronous along face to face chat have been scarce (Levy \& Stockwell, 2006) and only a few have been conducted regarding synchronous CMC applications (Jepson, 2005; Lee, 2007; Satar and Özdener, 2008; Sykes, 2005; Yanguas, 2010, 2012). Therefore, this study intends to investigate the influence of online and face to face chat on WTC. The researcher aims at finding out the differences in turn-taking, lexical density, and grammaticality in synchronous $\mathrm{CMC}$ and face to face environments.

\section{Method}

\subsection{Participant}

Since this is a case study, there is only one participant partaking. Shamim is a twenty one year old junior studying English translation in Parand University-one of the branches of Islamic open university near Tehran, Iran. In the past academic semester, I had an opportunity to take oral discussion courses there. Shamim was one of the students that drew my attention in these courses. She seemed to be quite unwilling to communicate though the topics were challenging and thought provoking. After seeking for the cause, she mentioned that her lack of vocabulary knowledge and communicative skills comparing to other students and also her shyness - which is considered a personality character - were the main hindering factors.

\subsection{Procedures}

This study was performed through two modes: synchronous online chat and face to face conversation. The participant was asked to take part in both modes. Both the face to face conversation and chat mode was administered in 5 sessions and the participant interaction in terms of turn taking was analyzed. The topics of the conversations were selected from IELTS speaking section. However, the researcher modified the topics to accommodate to the level of the learner. Face to face topics included traveling, food and cooking, internet, sports and exercise and seas and rivers whereas the online chat revolved around topics like learning English, superstitions, different culture customs, traffic and pollution, and marriage.

Both the face to face and online conversations were recorded for consequent analysis. Then the face to face conversations were transcribed for counting the turn takings, grammaticality and lexical density.

\section{Results and Discussion}

Data gathered from the participant was recorded and transcribed for analysis in terms of turn-taking, lexical density and grammaticality of the utterances. It should be noted that the nature of the present case study is qualitative and thus no statistical estimations are at work. The participant's transcribed utterances in both online chat and face to face modes were analyzed and compared in terms of 
leaner-teacher turn-taking.

\subsection{Face-to-Face Mode}

As was noted in the face to face conversation, the participants had much longer silence period-pauses - than the online chat mode. Some of the pauses were as lengthy as 30 seconds. Generally, the flow of information in the face to face mode was discontinuous and full of gap filling signals like ....errr......uh......emm.......

Below is an extraction of one of the face to face sessions; dots indicate long silence periods.

$\mathrm{T}$ : Do you have any hobbies or interests?

S: Sure ...I have..eh...a lot of interestes ...eh....every day....but I can't......do.....all of it.....eh....all of them.

T: Ok can you tell one of them?

S: sure I am studying........English for.......one hour every day......and listening music every......every day ...for.....two.......hour.

T: ok, you said you are interested in English right? How did you become interested in English?

S:.....first I went to class English. After...........research in the internet and ........... ask many teachers and......it cause.......to .............like English.

T: class English?

S: English class, sorry!

T: Aha, so this is the reason.

S: Yes

T: ok. How do you usually spend your holidays, I mean your vacation.

S: $\quad . . . .$. I always have a party....every Friday........because...........my sister.........don't live Tehran and try to...........try to come Tehran and ........live with us and then....

$\mathrm{T}$ : your sister is out of Tehran you said?

S: yes

T: So you have party every weekend!

S: Yes (laughs) not always!

$\mathrm{T}$ : Not always. Sometimes

S: Yes

T: ok. Is there anywhere that you like to visit? Any city or any place or any country that you think its very interesting and you like to visit?

S: Hmmmmmmmmm Hmmmmmmmmmmm. Can you repeat your question?

$\mathrm{T}$ : I said is there any place, I mean, any city or country that you have always liked to see? And tell me why you like that city or country?

S: Yes. I like to travel Shiraz. Because.........very.......very....have.........good........peo ple and live there.

T: Aha very good people. How do you know that?

S:...just I know........Hafez there.....because I like there a lot.........Hafez.

T: Alright.

As evident in the above transcription, the participant had the same number of turn taking as the teacher. Irrespective of the quality of the answers, it seems that the participant had a response to each of the questions. However, the learners had nothing to offer to initiate the conversation and she solely answered the questions with no diversion from the topic. It seems as if the participant was waiting for the knowerme-to initiate and handle the conversation. One reason seems to be the fact that the learner had marginalized herself, knowing that the knower will compensate for the conversational shortcomings and will fill the gaps. The other reason might be the learner's stress and shyness that can act as an inhibitor to true conversational performance. We can even go further and say that the learner's felt pressure on part of the interlocutor to a quick reply may build up the inhibitory affective filter.

As it is shown in the extraction from the face to face session, the participant makes a lot of pauses in answering to the questions, some pauses were so lengthy that the participant couldn't keep herself on the track of the conversation topic and had to ask for repetition many times.

In terms of grammatical correctness, the participant tends to have accuracy problems in the following areas:

\subsubsection{Correct Use of Noun Pluralization}

As shown in the excerpt, the participant has made many naïve mistakes which are not a true indicator of her language proficiency. As it is clear in the second line, she used the wrong form of "interestes" /-is/ instead of "interests" /-ts/. Presumably, she had confused the different form of pluralization under the contextual pressure.

\subsubsection{Modifier-Noun Order}

The correct order of an adjectival sentence in English is adjective (modifier) plus a noun that comes afterwards. In the face to face mode of the conversation, I noticed a considerable number of wrong adjective-noun order. It is hypothesized that under the affective factors the learner is unable to apply her knowledge to the output. In other words, the learner doesn't have any control over the output which is essential in language acquisition. Notice the place of adjective produced by the participant "class English" which is the same order as used in the L1 of the learnerPersian-in which the order of adjective-noun is exactly the reverse of English. In Persian, the order is noun + adjective- كلاس انظليسى -or “class English". It is assumed that the learner didn't have a conscious attention to this order and resorted to her first language. Therefore, L1 interference played a strong adverse role in her output production, given the fact that she proved to be aware of the adjective-noun order in English but simply failed to apply her knowledge in the actual output due to the stress inducing nature of face to face conversation with a knower. Of course, evidence exists as to prove that she was aware of the correct use of the adjective-noun order in English but couldn't apply it in her performance. Notice the following part of the face to face conversation extract:

$\mathrm{S}: . . .$. first I went to class English. After...........research in the internet and ........... ask many teachers and......it cause......to .............like 
English.

T: class English?

S: English class, sorry!

As you see, the learner corrects herself when the teacher provides her with a corrective feedback by repeating the illformed order-"class English?" — and she immediately corrected the form without any further explicit correction on the side of the teacher.

\subsubsection{Dropping of Prepositions}

One of the other areas that the participant had problem in the face to face mode of the conversation was the dropping of the prepositions. Consider the following part of the above excerpt:

S...........my sister..........don't live Tehran and try to..........try to come Tehran and ........live with us and then....

S: Yes. I like to travel Shiraz.

It is quite evident that the participant has problem in using of prepositions or maybe she has no idea if any propositions should be used at all. In the above excerpt "my sister don't live Tehran", "try to come Tehran" and "I like to travel Shiraz", she dropped all the place prepositions: "in" before "Tehran", "to" after "come", and "to" after "travel" respectively. It is worth mentioning that this preposition dropping was observed in many parts of the interview and was not limited to this excerpt only.

\subsubsection{Subject-Verb Agreement}

The participant had numerous mistakes in the use of correct subject-verb agreement. Take the above sentence again,

S:..........my sister.........don't live Tehran and try to...........try to come Tehran and ........live with us and then....

She didn't observe the required agreement between "my sister" and "don't" and "live" and this problem was observed in many other occasions:

1. S: My mother and father goes to work....

2. S: my friend stay with me

3. S: I is studying

Therefore, we can argue that face to face conversation didn't have a positive and constructive effect in directing the learner towards the correct use of grammatical points or in other words accuracy. But this is true in the absence of the online chat and we can't propagate against face to face mode unless we can prove the merits of online chat over the face to face mode of interaction.

\subsection{Online Synchronous Chat}

After investigating the sources of grammatical errors in the face to face mode, it's a good idea to investigate the same factors in the online chat mode and see if we can find any significant difference between these two modes. It should be noted that the less errors students make in a specific mode, the more willing we can claim they will be in engaging in conversation through that specific mode. To start, we take a look at the following excerpt taken from an online chat session:

T: What is your idea about learning English through chatting and computer?

S: It is very good thing because it is very exciting.

T: exciting?

S: Yes, becaus you talk with you teacher with computer and you don't see him.

$\mathrm{T}$ : You don't see him???? Is that exciting?

S: Yes, becaus when I talk with you not by computer I have stress but in computer I feel good.

T: Can you tell me more about the advantages of talking by chat?

S: Yes, I can see text and I have time to think and I haven't stress.

$\mathrm{T}$ : What are the characteristics of a good teacher?

S: A good teacher should be knowledgable and kind and understand the students and don't give them many homeworks

T: Aha, what about his appearance?

S: He should be beautiful and clean and attractive...

T: Beautiful? He?

S: Sorry I mean handsome

T: ok

\subsubsection{Correct use of Noun Pluralization}

One positive feature of online chat can be the sufficient time learners find to double check their outputs and modify them accordingly. Some special features like "spell checks" in chatting software can be considered an asset to accurate writing. Unlike face to face mode where learners are under psychological pressure which can cause more pluralization errors, online chat creates a more stress-free environment for learners to think and produce output. As evident in the above excerpt, Shamim has made almost no pluralization errors compared to the face to face mode.

\subsubsection{Modifier-Noun Order}

Considering the above excerpt, we examine all the points checked for the face to face mode. It is interesting to notice that the learner made a few modifier- noun order errors. Of course, this is only a brief and a sample excerpt of the whole conversations but the results are based on the comprehensive examination of the entire data.

Going back to the discussion, the leaner made a few errors-not in modifier-noun order-but in the correct use of the quantifier "many" before the uncountable noun "homework" which has mistakenly added a plural "s" to it. Of course this goes back to her lack of knowledge with regard to countable/uncountable nouns and has nothing to do with the mode of the conversation, but we can claim that in a face to face conversation the learner is more prone to committing such errors due to the intensity of the pressure on the side of the teacher. We can claim that in case the learner knows the rules she is more probable to apply it into her output when placed in the chat environment. 


\subsubsection{Dropping of Prepositions}

In the chat mode, as far as the data analysis showed there were virtually no incorrect use of prepositions. Take the bellow samples:

1. you talk with you teacher with computer

2. I have time to think

3. when I talk with you not by computer I have stress

As you see in the above samples the learner has almost used the correct prepositions. Although it is fair to say that for example instead of "with computer", "through computer" or "by computer" is recommended. But, when this level of prepositional use improvement is compared with the face to face mode, these minute usage issues - taken the low proficiency level of the student into account - are ignorable.

\subsubsection{Subject-Verb Agreement}

As evident in the above excerpt and comparing it to the face to face mode, one can understand that the number of subject-verb disagreement has significantly reduced. One reason for this improvement can be the textual enhancement that was proposed by Sharewood Smith (1981). By typing the text, the learner can visualize her output and check for the possible inconsistencies between the subject and the verb. In contrast, in the face the face mode, the learner doesn't have the needed time to go back and check for the possible disagreement between subject and verb. Of course, in case of high proficiency students, they may get use of monitoring strategies to rectify their errors but the majority of the language learners are non- advanced and don't have the required skills to check for their errors at the same time as they are talking.

\section{Conclusion}

The analysis of the data by the student indicate that Shamim - who is a sample of many others - was more willing to communicate online. Before looking at some final remarks and comments by the participant, it is interesting to reflect on the overwhelming preference by the participant to have conversation using online chat.

Although Shamim had experience using chat, it seems as if her interest in online chat had not waned over time; the same cannot be said about a myriad of other technological language-learning tools. Perhaps the use of computers to communicate in a synchronous manner remains attractive in that it is not integrated into every day affairs of students' lives yet; a phenomenon which has been referred to as normalization (Bax, 2003). If online chat activities manage to keep their newness which is due to the computer-mediated environment, there is no point in questioning the attractiveness of online chat for learners. Interestingly, this attractiveness of solving tasks using online chat promotes students' WTC. This notion may explain Shamim's comment: "I like chat. Somehow, it is interesting." Here are some other comments made by Shamim:

- it was the first time I used chat in English, so it was fun

- it was a written conversation, so it was more enjoyable than talking with your mouth

- it was fun because we couldn't see each other's face

- it's fun communicating by chat

- it was the first time I did this since I was a first-year student, so I enjoyed it

- the conversation was smoother and livelier than in a face-to-face conversation. It was fun.

Overall, Shamim seemed to prefer using chat because it was an enjoyable way to communicate and tasks that are enjoyable tend to increase students' intrinsic motivation (Dornyei, 2001). In such a pleasant atmosphere, the students can produce more 'conversation-like' language in a more relaxed and stress-free way. It is suggested that this way of lowering the affective filter will bolster students' WTC.

However, in spite of these positive results, these data represent only a few sessions of synchronous online chatting and although there are indications that the learners' WTC through online chat is stable, the researcher is unaware of any longitudinal studies of a linguistic nature which might question the niceness of online chat.

To end with, the findings in this study were not intended to argue against the use of conversation and face to face tasks in the classroom; rather, they aimed at emphasizing the point that besides the conventional modes of speaking tasks, employing technologies like synchronous chat will enhance learners' WTC. On the whole, synchronous chat increased interaction and opportunities to interact, both of which are considered aspects of successful applications of technology (Chapelle, 2001). Considering the results of this study between online chat and face to face conversation, one can claim that these differences are not ignorable and form the basis of learners' WTC through CMC.

Knowing that WTC is a fundamental element of successful L2 interaction and therefore a vital part of the language-learning classroom, teachers need to consider how they can provide the best environment to promote students' willingness to interact in the second language. The application of synchronous chat in L2 classrooms opens new doors towards minimizing social and affective constraints and reshapes the way the L2 students used to interact, obviously giving more opportunities to learners to experience WTC.

\section{References}

[1] Arnold, N. (2007). Reducing foreign language communication apprehension with computer-mediated communication: A preliminary study. System, 35(4), 469-486.

[2] Bax, S. (2003). CALL- past, present and future. System, 31 (1), $13-28$.

[3] Beauvois, M. H. (1998). Write to speak: the effects of electronic communication on the oral achievement of fourthsemester French students. In J. A. Muyskens (Ed.). News Ways of Learning and Teaching: Focus on Technology and Foreign Language Education. Boston: Heinle and Heinle. 
[4] Burgoon, J. K. (1976). The unwillingness to communicate scale: Development and validation. Communication Monographs, 43, 60-9.

[5] Chapelle, C. (2001). Computer Applications in Second Language Acquisition: Foundations for Teaching, Testing and Research. Cambridge: Cambridge University Press.

[6] Dörnyei, Z. (2005). The psychology of the language learner: Individual differences in second language acquisition. Mahwah, NJ: Lawrence Erlbaum Associates.

[7] Dornyei, Z. (2001). Motivation. In E. L. Judd, H. J. Walberg, and L. Tan (Eds.). Teaching additional languages. NY: International Academy of Education.

[8] Freiermuth, G., \& Jarrell, D. (2006). Willingness to communicate: can online chat help? International Journal of Applied Linguistics, 16 (2), 189-212.

[9] Jepson, K. (2005). Conversations - and negotiated interaction - in text and voice chat rooms. Language Learning \& Technology, 9 (3), 79-98. Retrieved from: http://lit.msu. edu/vol9num3/jepson/default.html

[10] Kang, S. J. (2005). Dynamic emergence of situational willingness to communicate in a second language. System, 33 (2), 277-292.

[11] Kelm, O. (1992). The use of synchronous computer networks in second language instruction: A preliminary report. Foreign Language Annals 25, 441-54.

[12] Levy, M. \& Stockwell, G. (2006). Call dimensions: Options and issues in computer-assisted language learning. Mahwah, NJ: Routledge.

[13] Lee, L. (2007). Fostering second language oral communication through constructivist interaction in desktop videoconferencing. Foreign Language Annals, 40 (4), 635649 .

[14] Long, M. H. (1985). Input and second language acquisition theory. In S. M. Gass and C.G. Madden (Eds.). Input in Second Language Acquisition. Rowley, MA: Newbury House.
[15] Satar, H. M., \& Özdener, N. (2008). The effects of synchronous $\mathrm{CMC}$ on speaking proficiency and anxiety: Text versus voice chat. The Modern Language Journal, 92 (4), 595-613.

[16] Sharwood Smith, M. (1981). Consciousness-raising and the second language learner. Applied Linguistics, 2, 159-68.

[17] Sykes, J. (2005). Synchronous CMC and pragmatic development: Effects of oral and written chat. CALICO Journal, 22(3), 399-431.

[18] Stoller, F. L., Hodge, R., \& Kimbrough, J. (1995). Examining the value of conversation partner programs. Applied Language Learning, 6, 1-12.

[19] Sullivan, N. \& Pratt, E. (1996). A comparative study of two ESL writing environments: A computer-assisted classroom and a traditional oral classroom. System, 29 (4), 491-501.

[20] Vygotsky, L. S. (1978). Mind in Society. Cambridge, MA: Harvard University Press.

[21] Warschauer, M. (1997). Computer-mediated collaborative learning: Theory and practice. Modern Language Journal, 81 (3), 470-81.

[22] Yanguas, I. (2014). Willingness to communicate in face-toface versus computer-mediated communication. JALTCALL Journal, 10 (2), 83-103.

[23] Yanguas, I. (2010). Oral computer-mediated interaction between 12 learners: It's about time! Language Learning and Technology, 14 (3), 72-93.

[24] Yanguas, I. (2012). Vocabulary acquisition in oral computermediated interaction. CALICO Journal, 29 (3), 507-531.

[25] Yashima, T. (2002). Willingness to communicate in a second language: The Japanese EFL context. The Modern Language Journal, 86, 54-66.

[26] Yashima, T., Zenuk-Nishide, L., \& Shimizu, K. (2004). The influence of attitudes and affect on willingness to communicate and second language communication. Language Learning, 54 (1), 119-52. 